Review

\title{
The harmonization of World Health Organization International Nonproprietary Names definitions for cell and cell-based gene therapy substances: when a name is not enough
}

\author{
Ursula Loizides $^{1, *}$, Massimo Dominici ${ }^{2}$, Tony Manderson ${ }^{3}$, Menico Rizzi $^{4}$, James S. Robertson ${ }^{5}$, \\ Sofia de Sousa Guimarães Koch ${ }^{1}$, Marcos Timón ${ }^{6}$, Raffaella Balocco ${ }^{1}$ \\ ${ }^{1}$ International Nonproprietary Names Programme and Classification of Medical Products Unit, Health Products Policy and Standards Department, World Health \\ Organization, Geneva, Switzerland \\ 2 Laboratory of Cellular Therapy, Division of Oncology, University of Modena and Reggio Emilia, Modena, Italy \\ ${ }^{3}$ Department of Health, Therapeutic Goods Administration, Woden, Australian Capital Territory, Canberra, Australia \\ ${ }^{4}$ Department of Pharmaceutical Sciences, University of Piemonte Orientale, Novara, Italy \\ ${ }^{5}$ Independent Expert, St Albans, UK \\ ${ }^{6}$ Agencia Española de Medicamentos y Productos Sanitarios, Madrid, Spain
}

\section{A R T I C L E I N F O}

\section{Article History:}

Received 28 January 2021

Accepted 26 February 2021

Key Words:

cell-based gene therapy

cell therapy

drug nomenclature

global health

International Nonproprietary Names (INN)

patient safety

\begin{abstract}
A B S T R A C T
The World Health Organization (WHO) assigns International Nonproprietary Names (INN) to pharmaceutical substances, including advanced therapy medicinal products, to ensure that each substance is globally recognized by a unique name. The majority of INN are published in the WHO Drug Information in accordance with the nomenclature rules of the International Union of Pure and Applied Chemistry. However, advanced therapy medicinal products, and in particular cell therapy and cell-based gene therapy substances, cannot be defined by such chemical nomenclature. Instead, they are published together with a textual definition paragraph to unambiguously describe their characteristics. These definitions are an integral part of the INN nomenclature system, and their presence contributes to pharmacovigilance and patient safety, as they help to distinguish regulated substances from cell-based interventions that have no INN and are marketed without regulatory oversight. Particular attention is therefore allocated to these descriptive paragraphs, as they form the basis for defining the uniqueness of a particular cell substance. This review describes the INN nomenclature system for cell-based substances and focuses on the progress made by the WHO INN Programme to develop and harmonize these definition paragraphs, which is reflected in a newly revised INN application form for cell therapy substances.
\end{abstract}

This is an open access article under the CC BY-NC-ND IGO license (http://creativecommons.org/licenses/by-nc-nd/3.0/igo/)

\section{Introduction}

The International Nonproprietary Names (INN) nomenclature system was initiated in 1950 by World Health Assembly Resolution WHA3.11 and began operating in 1953, when the first proposed list of INN for pharmaceutical substances was published. Since then, the World Health Organization (WHO) has been assigning INN to medicinal substances according to established guidelines, and both WHO and INN applicants are bound to this formal procedure (EB115/112004) [1]. Over the years, the INN nomenclature system has been

\footnotetext{
* Correspondence: Ursula Loizides, PhD, International Nonproprietary Names Programme and Classification of Medical Products Unit, Health Products Policy and Standards Department, World Health Organization, 20 Avenue Appia, 1211 Geneva 27, Switzerland.

E-mail address: uloizides@who.int (U. Loizides).
}

continuously adapted and revised to encompass scientific developments in drug discovery, especially in the field of biotechnology.

The INN nomenclature system was originally developed to assign INN mainly to chemically well-defined, homogeneous substances, although distinct biological products, such as animal insulin preparations (Recommended INN List 3 in 1959) and other low-molecularweight proteins (e.g., hormones, cytokines) as well as synthetic peptides, were also included. However, with the advent of large, complex biologics such as gene therapy (GT) and, more recently, cell therapy (CT) and cell-based gene therapy (CGT) substances, this has changed dramatically. By way of illustration, small-molecule medicinal substances are relatively simple compounds that can be manufactured by chemical synthesis and typically have a molecular mass of less than approximately $1 \mathrm{kDa}$; a monoclonal antibody is significantly more complex, having an average molecular mass of $150 \mathrm{kDa}$; viral vectors for gene delivery are even larger, reaching vector genomes of 
up to approximately $5 \mathrm{~kb}$ or about $1650 \mathrm{kDa}$; but most complex of all are CT and CGT substances, not only in size but also in composition (e.g., one single yeast cell contains up to $4.2 \times 10^{7}$ protein molecules per cell [2]). The introduction of such complex biological substances into the INN nomenclature scheme has proven to be challenging.

Although large in size, viral and plasmid GT vectors that enable the delivery of nucleic acid material to target cells are well defined. The structure of the vector can be characterized, and the exact nucleic acid sequence of each vector genome is known and can be described in detail. This contrasts with cell substances that are much less homogeneous and highly complex. Though cell substances are mostly enriched for a particular cell type that constitutes the active ingredient, they still contain multiple cell populations and display an inherent heterogeneity that poses a significant problem for the INN policy of not assigning names to mixtures. However, if no INN is assigned, it will make it more difficult to distinguish between regulated and nonregulated substances. The INN Programme also faces the challenge of describing these heterogenous substances; however, if this is not achieved, there is a risk that a single INN may refer to multiple cell substances or that separate INN may be assigned to various cell substances that are in fact the same, if described precisely.

INN published in the WHO Drug Information are largely substances conforming to International Union of Pure and Applied Chemistry (IUPAC) nomenclature rules; however, CT and CGT substances cannot be defined in this way. Instead, the INN are published together with a textual definition to univocally describe their characteristics. These definitions are an integral part of the INN, and particular importance is therefore allocated to these descriptive paragraphs, as they are the basis for defining the uniqueness of a particular cell substance.

With the advent of new technologies, such as genome editing by, for example, clustered regularly interspaced short palindromic repeats (CRISPR)/CRISPR-associated protein 9 (Cas9) and other geneediting technologies [3], as well as the arrival of personalized medicine, the field is rapidly becoming even more complex. Hence, to adapt the INN nomenclature, including the definition paragraphs, to these new technologies, a revision of the information to be provided for CT and CGT INN applications became indispensable. This review describes the recent progress made by the INN Programme to name and define CT and CGT substances, which encompassed a revision of the INN application form for cell-based substances as well.

\section{Overall Development in INN Applications over the Last Decade}

In parallel with the increase in complexity among INN requests, the number of INN applications has grown steadily over the last decade, from around 80-100 INN applications per biannual INN Consultation in 2010-2012 to more than 200 INN requests for the 71st INN Consultation held in October 2020 (Figure 1A). Moreover, not only has there been a constant growth in the absolute number of INN requests, but the proportion of INN for biological substances has also increased considerably (Figure 1). In 2010, at the 50th and 51st INN Consultations, the percentage of biological requests was around $30-35 \%$ of the total, whereas they currently represent more than half of all INN applications (Figure 1B). In recent years, CT and CGT applications have started to contribute to this increase in biological INN requests. This development is expected to continue, as the cell therapy market exhibits a tremendous growth potential, which will likely translate into a corresponding increase in INN applications. Yet not all of these substances will reach marketing authorization, as INN applications are usually filed during early clinical development. Out of approximately $70 \mathrm{CT} / \mathrm{CGT}$ substances and approximately $80 \mathrm{GT}$ substances that have been assigned INN, only six have so far been approved by the US Food and Drug Administration (FDA), and only 10 had received marketing authorization from the European Medicines Agency by the end of 2020 (Tables 4, 5). With the recent success of chimeric antigen receptor (CAR) T-cell therapies, these numbers
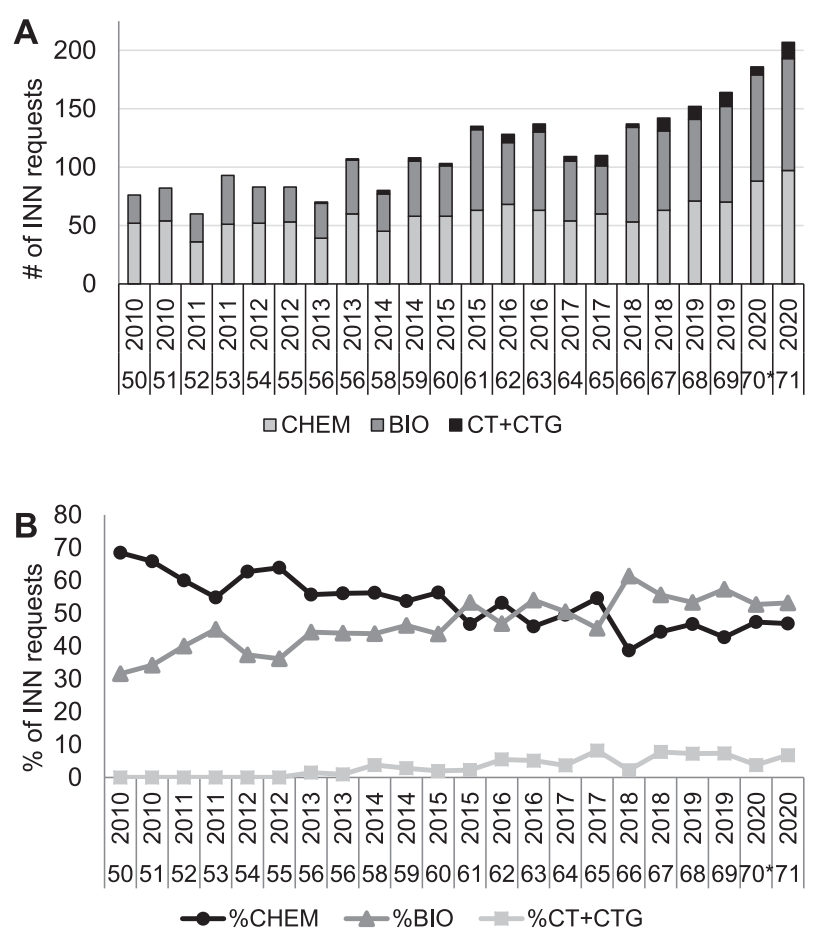

Figure 1. INN applications per consultation between 2010 and 2020. (A) New requests divided into CHEM, BIO (not including cell-based substances) and cell-based INN (CT + CGT) requests, from the 50th INN Consultation in April 2010 to the 71st INN Consultation in October 2020. (B) Percentage of total INN requests per consultation separated into CHEM and BIO (including cell-based substances) requests. The percentage of cellbased INN requests $(\mathrm{CT}+\mathrm{CTG})$ is also shown separately as a light gray line. *The 70th INN Consultation includes the COVID-19 special Consultation held in August 2020. BIO biological; CHEM, chemical; COVID-19, coronavirus disease 2019.

are likely to increase as more and more CGT substances reach advanced clinical development stages. This trend is also reflected in the number and type of INN applications. CGTs currently represent the largest group of cell-based INN applications (Figure 2A), half of which are CAR T-cell applications (Figure 2B).

\section{The INN Nomenclature Scheme: Stems and Infixes}

The INN Programme assigns INN to medicinal substances to provide each substance with a unique name that belongs in the public domain and can be used freely. INN have proven to be indispensable for the clear identification, safe prescription and dispensing of medicines and for communication and exchange of information among health professionals. Names that are likely to convey a pathological or therapeutic suggestion or are liable to be confused with names in common use are avoided. Whenever possible, the structure of an INN incorporates a suffix that reflects the pharmacological group to which the substance belongs, making it possible to recognize pharmacologically related substances by their name. When a common suffix is adopted for a specific pharmacological group, it is designated a "stem." Examples are the stem -cel for cell-based substances, as in tisagenlecleucel (117)(79) and axicabtagene ciloleucel (117)(79); the stem -mab for monoclonal antibodies, as in trastuzumab (78)(40) and adalimumab (85)(45); and the stem -tide for peptides, as in liraglutide (87)(49) and lanreotide (64)(31), whereby the numbers in parentheses represent the proposed and recommended INN lists in which the name was published. In contrast to a common suffix or stem, INN have a random, fantasy prefix that bestows uniqueness to each INN. As always, there can be exceptions, and in some cases the stem may be placed in the middle or at the beginning (prefix), as in, for example, the stem cef- for cephalosporin derivatives (e.g., cefuroxime). With the incorporation of infixes (syllables placed between the fantasy 

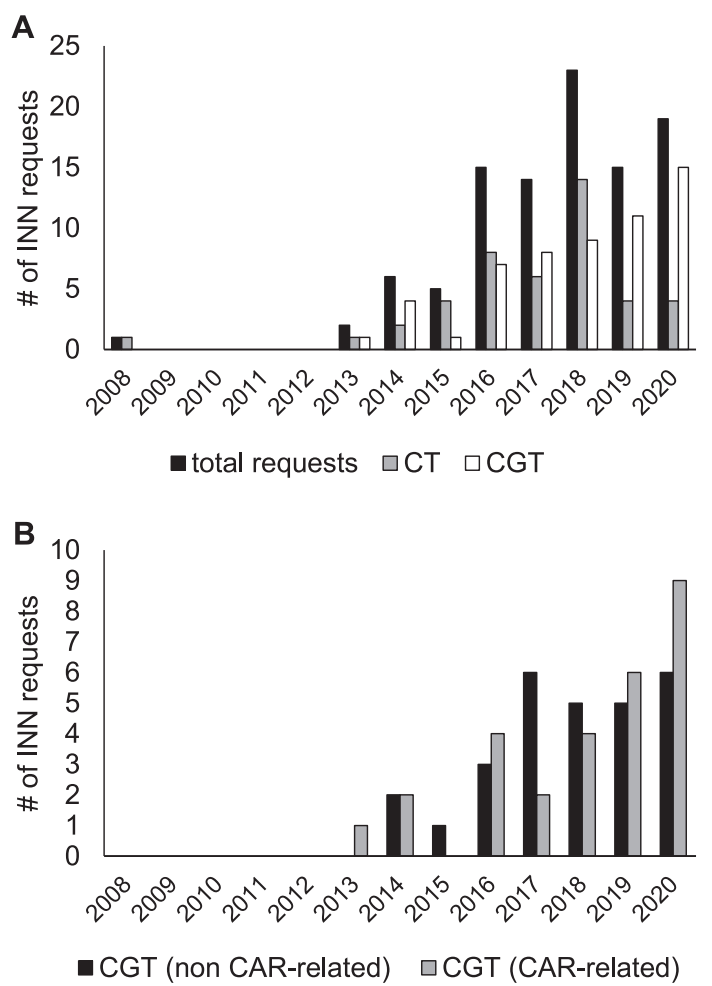

C

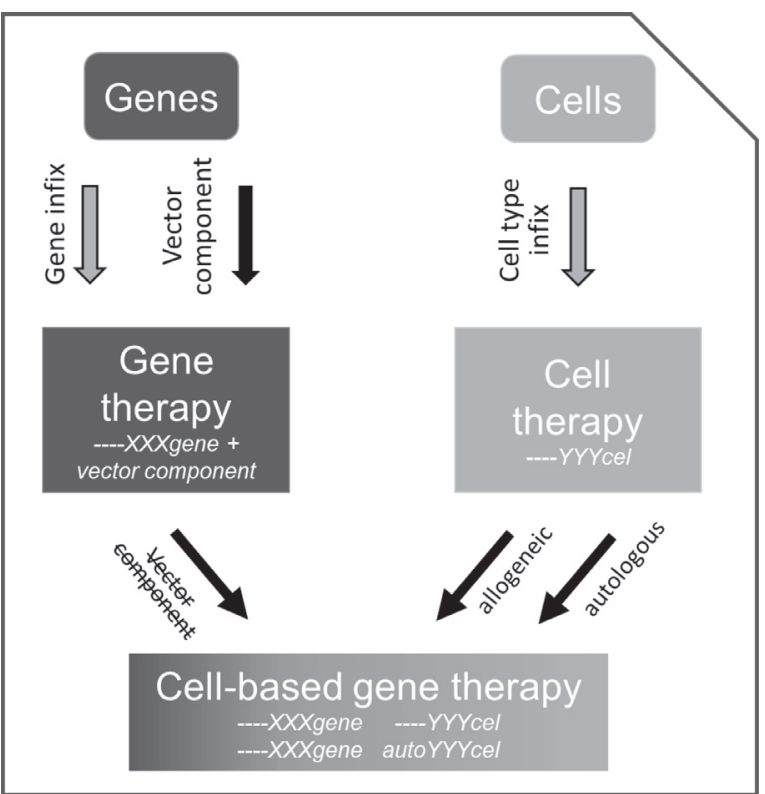

Figure 2. CT and CGT INN requests between 2008 and 2020. (A) Number of total cellbased INN, non-genetically modified CT and CGT requests per INN consultation. (B) Number of CGT INN requests that are not CAR T-cell-related and number of CGT requests that are CAR T-cell-related per INN consultation. (C) INN nomenclature scheme for cell and gene-based substances.

prefix and the common suffix), more information can be provided by the INN itself. For example, the infix -li- within the monoclonal antibody category specifies that the target of adalimumab, which binds tumor necrosis factor alpha, is immunomodulating, whereas the infix -glu- in liraglutide signals that this peptide is a glucagon-like peptide analogue. Stems and infixes are selected by the WHO INN Expert Group and are carefully evaluated for each INN application.
Importantly, the nomenclature process is ongoing and constantly under revision, and new stems and infixes are created when necessary. More than one infix can be used within an INN; however, there is a limit to the number of infixes and therefore the amount of information that can be incorporated into the INN itself before the name becomes too long and unpronounceable. Importantly, an INN should be distinctive in sound and spelling and should not be inconveniently long. Therefore, additional information that cannot be included in the INN itself but is necessary to uniquely characterize a substance should be included in an accompanying definition paragraph that is published together with the INN in the WHO Drug Information. Further information on the use of stems is provided in the WHO Stem Book [4], which gives an introduction to the INN selection procedure and an alphabetical list of common stems together with their corresponding INN. Furthermore, the INN Programme has launched the School of INN (https://extranet.who.int/soinn/), an online platform that has the aim of educating pharmaceutical and medical students as well as other INN stakeholders on how INN are designed.

\section{Development of the Nomenclature Scheme for Cell-Based Substances}

Since its inception, the INN Programme has aimed to assign INN only to well-defined substances, including biologicals such as peptides, monoclonal antibodies and other recombinant proteins. In 2008, the INN Programme received its first request to name a cell-based substance. Initially, INN experts felt that CT substances were not within the scope of the current INN policy, as INN should be assigned to well-characterized substances only; cells and tissues, including stem cells, were considered outside the remit of the INN system. However, the INN Programme had to consider that different regulatory environments had already developed naming schemes for these substances (e.g., the United States Adopted Names [USAN] Council had started naming CT substances in 2005) and that the prevalence of different generic names referring to the same cell substance would create confusion and impact the exchange of information via scientific publications and could ultimately lead to prescription errors endangering patient safety. Thus, a decision was made to adopt the provision of INN for cell substances, and in the following years the WHO Secretariat, the INN Working Group on cell therapy, the USAN Council and the US Center for Biologics Evaluation and Research (CBER) reached agreement on a common CT nomenclature scheme. The INN cell substance naming scheme excludes minimally manipulated hematopoietic elements and combination products. Initially, autologous CT substances were also omitted, but following further review and harmonization with USAN/CBER, these were later assigned INN as outlined in the 2016 version of the International Nonproprietary Names (INN) for biological and biotechnological substances (BioReview 2016) [5]. This document, first published on the INN Programme website in 2006, presents an inventory of policy decisions taken by the INN Expert Group for biological substances. The BioReview is intended to be a living document that is updated regularly to include new policies and INN that have been assigned.

A significant group of biological substances excluded from the INN system are vaccines, for which names are assigned through the recommendations of the WHO Expert Committee on Biological Standardization. This concerns classical vaccines that are based on live attenuated or inactivated pathogens. However, with the advent of recombinant technologies and novel developments such as peptide vaccines as well as nucleic acid-based DNA and RNA vaccines, this has changed substantially, as these chemically well-defined substances fall within the scope of the INN naming system. As of 2020, five messenger RNA (mRNA) and one plasmid-based vaccine substance have been assigned INN, such as the severe acute respiratory syndrome coronavirus 2 RNA vaccines zorecimeran (124), abdavomeran 
(124), tozinameran (124), ganulameran (124) and pidacmeran (124) and the DNA vaccine reluscovtogene ralaplasmid (124).

The first CT substance that received the status of proposed INN (pINN) was spanlecortemlocel (115)(74), a preparation of allogeneic umbilical cord blood-derived hematopoietic stem and progenitor cells. The INN was published in 2014 in pINN list 112 and later amended in pINN list 115. The name contains the infixes -cor-and -tem-, representing the source material, umbilical cord blood (-cor-), and the active cell type, stem cells (-tem-). Furthermore, according to the nomenclature scheme that was in place at that time, infixes such as -le(c)-for "selected/enriched" and -lo-for "allogeneic," referring to the manipulation process and the origin of the substance, were also part of the INN, resulting in a name that is very long and difficult to pronounce. The INN Programme eventually did not further pursue this direction but subsequently decided to assign shorter names with ideally only one infix describing the type of cell substance, accompanied by a precise but descriptive definition paragraph. These short descriptive paragraphs are published together with the INN in the WHO Drug Information and contain details about the substance that are not part of the name itself. For example, for spanlecortemlocel (115)(74), the definition paragraph specifies that the substance "typically contains $>10 \%$ of cells expressing CD34." Hence, the active cell component (CD34+ cells) is only a small part of this substance, whereas around $90 \%$ of the cells are not further characterized. This illustrates the challenges that the INN Programme has faced in unequivocally characterizing such substances, which has also translated into difficulties for the Programme in assigning names to such imprecisely specified, heterogeneous products.

Subsequently, more CT substances were assigned INN and published 2 years later in pINN list 115 [6]. These include audencel (115) (77), eltrapuldencel (115)(77), cenplacel (115)(77) and palucorcel (115) (77). By this time, the nomenclature system had been revised, and information concerning the origin of the cell substance (i.e., allogeneic, autologous or xenogeneic) was no longer incorporated into the name itself but instead specified in the INN definition paragraph of the substance (as outlined in the 2016 version of the BioReview) [5]. Only the infix describing the source material/active cell type was retained within the nomenclature scheme, indicating that these cells mainly contain dendritic cells (-den-), placental cells (-pla-) and umbilical cord cells (-cor-). In addition, pINN list 115 includes the first CGT substance, tonogenconcel (115)(77), which consists of allogeneic primary human chondrocytes, identified by the infix -con-, transduced with a retroviral vector expressing human transforming growth factor beta 1 . The infix -gen-indicates that the cells have been genetically manipulated; however, the gene of interest (transforming growth factor beta 1 ) is not further specified within the word. Other infixes referring to cell manipulation were to some extent also still included, and examples are eltrapuldencel (115)(77) and stapuldencel (121)(83), which contain the USAN infix -pul- for pulsing, referring to the incubation of cells with peptides, cell lysates or other agents. In both cases, the manipulation infix was maintained for harmonization purposes, as the names had already been adopted by the USAN council in 2014 [7,8]. For the same reason, the infix -le (c)- for selected/enriched was maintained until pINN list 117; examples are tabelecleucel (117)(79), adimlecleucel (117)(79), tisagenlecleucel (117)(79) and rivogenlecleucel (117)(79).

As mentioned, the INN experts had been reluctant for several years to name autologous cell therapy substances. However, the INN Programme eventually agreed that the nomenclature scheme should be extended to include autologous cell substances, both non-genetically and genetically engineered. The first autologous CT substances that were assigned INN were audencel (115)(77) and eltrapuldencel (115)(77), which are dendritic cell-based cancer immunotherapies. Both INNs were published in pINN list 115 [6], though the basis for their nomenclature differs, as audencel was named according to a newly revised scheme, whereas eltrapuldencel, already adopted by the USAN Council in 2014, was named in accordance with the USAN guidelines. It is not unusual for names to have followed different rules by different nomenclature bodies before a final harmonized nomenclature scheme was established. Given that an adopted name can be modified only under exceptional circumstances, these names will remain unchanged.

\section{Current Nomenclature System for Cell-Based Substances}

As previously described [9], different approaches, based on the use of a one-word versus two-word naming scheme, were developed by the INN Programme for various categories of biological substances, highlighting a major and still not completely resolved issue on how to assign a name that is informative, short and euphonic.

The current nomenclature scheme for cell-based substances can be found in the 2019 version of the INN document International Nonproprietary Names (INN) for biological and biotechnological substances (BioReview 2019) [10]. The BioReview 2019 summarizes the naming scheme for advanced therapy products, including CT, GT and CGT, and is also published on the INN Programme website.

The nomenclature system for non-genetically modified CT substances comprises a single word beginning with a random fantasy prefix and ending with the stem -cel (Table 1). Between the fantasy prefix and the stem -cel there is one infix, which refers to the primary cell type responsible for the mode of action of the substance. The list of infixes, which identifies the primary cell type (e.g., -leu- for leukocytes and -tem-for stem cells), can also be found in the BioReview 2019 [10]. However, this list is not final and is constantly adapted to encompass new cell types that have not previously been assigned an infix. The current list consists of 23 cell type-specific infixes and is listed in Table 1. Residual cells that are not expected to contribute to the intended function are not named. In the case of manipulations such as cell expansion and cell activation (e.g., with cytokines/drugs), no special infix will be assigned, and the information will be provided in the definition paragraph. Indeed, it was the desire of the INN Expert Group to avoid overly long and complicated names and instead detail this information in the short descriptive paragraphs that accompany each INN publication.

The harmonized nomenclature for CGT comprises a two-word scheme in which the first word identifies the gene component and the second word identifies the cell component (Table 2). The scheme therefore identifies CGT by a unique nomenclature but formally links these substances to both the CT and the GT categories, which is illustrated in a graphical schematic (Figure 2C). The first word, which describes the gene component, contains a gene infix, which identifies the target gene, followed by the suffix -gene, using the same gene infixes as those used in non-cell-based gene therapies. For example, prademagene zamikeracel (119)(81), a keratinocyte-based CGT, and beremagene geperpavec (123), a virus-based GT for the treatment of epidermolysis bullosa, both contain the gene infix -ema-for extracellular matrix genes, as both introduce a functional version of the extracellular matrix collagen VII.

The list of gene infixes is rapidly expanding and reached a total of 57 different infixes at the 71st Consultation. Only a subset of gene infixes is shown in the BioReview 2019 [10] and in Table 2. The updated list of all gene infixes assigned up to the 71st Consultation can be found in supplementary file 1 of this review and will also be included in the upcoming revised version of the BioReview targeted for 2021. Moreover, further additions to the GT naming scheme are discussed, including the suffix -rgene for substances that do not encode for a protein but instead for non-coding RNAs such as microRNA.

The nomenclature scheme for CGT substances is also constantly evolving. During the 67th INN Consultation in 2018, an INN-FDA harmonized scheme for autologous CGT substances was formally approved by the members of the INN Expert Group, whereby the 
Table 1

Nomenclature scheme for non-genetically modified cell therapy substances

\begin{tabular}{|c|c|c|c|}
\hline \multirow{2}{*}{$\begin{array}{l}\text { Prefix } \\
\text { random to contribute } \\
\text { to euphonious } \\
\text { and distinctive name }\end{array}$} & \multicolumn{2}{|r|}{ Infix ${ }^{(a, b)}$; cell type } & \multirow{2}{*}{$\begin{array}{l}\text { Suffix } \\
\begin{array}{l}\text {-cel } \\
\text { (cell) }\end{array}\end{array}$} \\
\hline & $\begin{array}{l}\text { to identify } \\
\text { existing ir }\end{array}$ & $\begin{array}{l}\text { he primary cell type }{ }^{(c)} \text { using, when available, } \\
\text { xes for cell types }\end{array}$ & \\
\hline & $\begin{array}{l}\text {-adstro- } \\
\text {-co(n)- } \\
\text {-defitem- } \\
\text {-den- } \\
\text {-end(o)- } \\
\text {-ep(a)- } \\
\text {-fi(b)- } \\
\text {-isle- } \\
\text {-ker(a)- } \\
\text {-leu- } \\
\text {-mestro- } \\
\text {-mio(b)- } \\
\text {-ova- } \\
\text {-nupu- } \\
\text {-pla(c)- } \\
\text {-ren- } \\
\text {-ret- } \\
\text {-rom- } \\
\text {-tem- } \\
\text {-tesi- } \\
\text {-tu- } \\
\text {-ubi- } \\
\text {-ur- }\end{array}$ & $\begin{array}{l}\text { adipose stromal cells } \\
\text { chondrocytes } \\
\text { differentiated stem cells (not fitting into } \\
\text { any existing category) } \\
\text { dendritic cells } \\
\text { endothelial cells } \\
\text { hepatocytes } \\
\text { fibroblasts } \\
\text { islet cells } \\
\text { keratinocytes } \\
\text { leukocytes (lymphocytes / monocytes/APC) }{ }^{\text {(d) }} \\
\text { mesenchymal stromal cells (MSC) } \\
\text { myoblasts } \\
\text { ovary cells } \\
\text { nucleus pulposus cells } \\
\text { placenta cells } \\
\text { renal tubular cells } \\
\text { retinal epithelial cells } \\
\text { cells with stem and stromal capacity } \\
\text { stem cells } \\
\text { testis cells } \\
\text { tumour cells } \\
\text { umbilical cord cells (previously -cor-) } \\
\text { urothelial cells }\end{array}$ & \\
\hline
\end{tabular}

(a) Manipulation infixes should be avoided to circumvent overly long names.

(b) In the case of manipulation such as cell expansion and cell activation (with cytokines/drug, etc.), there is no need for an infix; this kind of manipulation will be specified in the description.

(c) Residual cells not expected to contribute to the intended function, are not named.

(d) The cell type infix -leu- is used to describe hematologic cell preparations that do not fit in any particular cell type category. Such cell preparations may be comprised of a mixture of the various blood cell elements, such as T-, B- or NK-cells, or antigen-presenting cells (APCs) that do not fit in the definition of dendritic cells.

second word of autologous CGT INN is characterized by the prefix auto-, whereas allogeneic CGT INN are assigned a random prefix (67th INN Consultation Executive Summary [11]). This scheme was recently updated in view of autologous CGT substances for which the gene component remains the same but that consist of autologous cells derived from different patient populations with distinct characteristics, such as brexucabtagene autoleucel (124) versus axicabtagene ciloleucel (117)(79). Instead of adding a new random prefix or infix to the autologous cell component, the INN experts decided that the random prefix of the first word should comprise changes in the cell component as well. For autologous CGT substances, a different fantasy prefix can therefore indicate that either a new vector component or a new cell component is present, and only the INN definition paragraph will specify the details. This further highlights the importance of these short descriptive paragraphs, which provide all the necessary information that is not included in the INN itself.

\section{Revision of the INN Application Form for Cell-Based Substances}

As highlighted in other sections, the INN Programme publishes a definition paragraph together with the INN to unambiguously describe the biologically active ingredients of advanced therapy

Table 2

Nomenclature scheme for cell-based gene therapy substances

\begin{tabular}{|c|c|c|c|}
\hline & Prefix & Infix & Suffix \\
\hline word 1 (gene component) & $\begin{array}{l}\text { random to contribute to } \\
\text { euphonious and distinctive name }\end{array}$ & $\begin{array}{l}\text { to identify the gene using, when available, existing infixes for biological products } \\
\begin{array}{ll}\text { or using similar infix as for the protein for which the gene codes, e.g.: } \\
\text {-cabta- } & \text { cell expressed antibody and T cell activation } \\
\text {-covto- } & \text { SARS-CoV-2 } \\
\text {-distro- } & \text { muscular dystrophy related } \\
\text {-ema- } & \text { extracellular matrix } \\
\text {-ermin- } & \text { growth factor } \\
\text {-kin- } & \text { interleukin } \\
\text {-lim- } & \text { immunomodulator } \\
\text {-octoco- } & \text { coagulation factor VIII } \\
\text {-reti- } & \text { retinal dystrophy related } \\
\text {-tres- } & \text { T cell receptor engineered for specificity }\end{array}\end{array}$ & $\begin{array}{l}\text {-(vowel)gene } \\
\text { e.g. -(o)gene }\end{array}$ \\
\hline word 2 (cell component) & $\begin{array}{l}\text { autologous: } \\
\text { auto- } \\
\text { allogenic: } \\
\text { random- }\end{array}$ & to identify the primary cell type ${ }^{(\mathrm{c})}$, use when available existing infixes for cell types ${ }^{(\mathrm{d})}$ & $\begin{array}{l}- \text { cel } \\
\quad \text { (cell) }\end{array}$ \\
\hline
\end{tabular}

\footnotetext{
(c) Residual cells not expected to contribute to the intended function, are not named.

(d) For cell type infixes see Table 1.
} 
medicinal product substances. This definition paragraph is highly significant for cell-based substances, which possess an inherent complexity that is difficult to capture within the name itself. However, a precise definition of a substance can only be achieved if the information provided by the applicant is complete and comprehensive. Therefore, the INN Programme undertook an effort to harmonize INN definitions for cell-based substances (CT and CGT), which comprised the revision of the INN application form. During the 70th INN Consultation [12] in April 2020, this new revised application form for cellbased INN application was formally approved, and the new version, which is now mandatory for all new CT/CGT INN applications, is shown in supplementary file 2 and can also be found on the INN Programme website (annex to INN application form, INN working document 20.478) [13].

The new revised application form [13] differs extensively from the previous version (supplementary file 2 ), which did not request specific details and only provided a simple list of five bullet points (name/code designation, characterization/description, cell source, list and description of manipulations [culture conditions included] and genetic manipulation) to be addressed by the applicant at their discretion. By contrast, the new version is much more focused and details the type of information to be provided. Although the first point, "name/code designation," remained a short bullet point, the other topics were substantially elaborated.

\section{Cell source or tissue of origin}

The key point, "cell source," became "cell source or tissue of origin" and now asks for precise information on the origin of the starting material. There are three subparagraphs depending on whether the cells are derived from (i) a cellular source, such as peripheral blood or apheresis material; (ii) a cell bank, as would be the case for allogeneic cell lines such as evagenretcel $(116)(78)$ and revakinagene taroretcel (123); or (iii) tissue material. Moreover, it is highlighted that the applicant should provide some characterization of the starting material independent of the origin of the cells. For example, if the cells are derived from tissue, the tissue type and method of extraction of the cells should be specified.

\section{Manufacturing process, including manipulations}

The INN experts emphasized that key steps of the manufacturing process should be provided, as both the starting material and the manufacturing process become integral parts of the live cell component that constitute the active substance. Therefore, the paragraph on cell manipulation now requests a description of key steps in the manufacturing process and is divided into three points (a, b and c). The first point (a) inquires as to whether any form of cell enrichment or purification/selection of the starting material was performed at any step during the preparation of the drug product or substance. The second point (b) asks for details regarding the in vitro culture conditions, including those used during genetic modification of the cells, cell activation and differentiation. In addition, the number of cell passages and/or population doublings has to be provided to assess the degree of culture expansion. The third point (c) focuses on in-process holding steps and storage conditions of the finished cell substance (e.g., freezing). Even if the cells are not further manipulated, this section must be completed, as these handling steps impact the characteristics of the final cell substance.

\section{Characterization/description of the substance}

The section on characterization/description has four subparagraphs. In particular, the INN experts agreed that it is important to assess the purity of the substance and to describe the proportion of all major cell populations that contribute to the final product. CT/CGT substances are often heterogeneous mixtures of several active cell populations that together form the active ingredient. The purity of a substance has never been a matter of concern in assigning an INN, but in the case of CT/CGT substances, purity becomes an issue, as different cell types within the inevitable heterogeneous population may impact the pharmacological activity of the whole population. Thus, the first subparagraph of the characterization/description section requests specific information on the main cell population(s) at both the phenotypic level (with a minimum of two cell surface markers to be provided) and the functional level, which may include the secretion profile, as well as other forms of functional characterization. For products in an early stage of clinical development, such information may not be available, but it is crucial to identify the uniqueness of the substance if an INN is to be assigned. The following three subparagraphs specifically focus on stem cells, stem and progenitor cells and stromal cells. For stem cells, the applicant should demonstrate that the cells are capable of self-renewal, are unspecialized and can give rise to several specialized cell types. In the case of the other two cell populations, stem and progenitor cells and stromal cells, the applicant should provide information on their functionality in vitro and/or in vivo.

\section{Genetic manipulation}

Provision of information on genetic manipulation applies only to CGT substances and remains similar to the previous application form in requesting a detailed description of the vector and gene insert; however, when a new vector is derived from an existing, already named vector, a sequence alignment and table of comparison should be provided. This request was added as manufacturers of CGT and GT substances often have a vector platform in place that can be adapted to a new target. However, it is the policy of the INN Programme that even the smallest change to a substance, including changes that affect the vector backbone, warrants a new INN. The revision of this point therefore helps the INN Programme to compare an existing, already named vector backbone with a new vector application.

\section{INN Applications for CAR T-Cell Therapies}

The most prominent group among the CGT substances are CAR Tcell therapies. They represent a form of cancer immunotherapy that uses synthetic T-cell receptors (TCRs) to redirect lymphocytes to recognize and eliminate cells expressing a specific target and have demonstrated impressive therapeutic effects in certain types of blood cancer [14]. This exciting new development in biomedical research is also reflected within CGT INN applications, as CAR T-cell requests now represent the most prevalent group and comprise half of all CGT applications (Figure 2B).

In 2013, the INN Programme received its first CAR T-cell application; however, this application and two subsequent requests were withdrawn, as the INN Programme had not yet established a nomenclature scheme for these substances. In 2016, the first three CAR Tcell INN were assigned: axicabtagene ciloleucel (117)(79), tisagenlecleucel (117)(79) and vadacabtagene leraleucel (117)(79). Their basis for nomenclature differs, as two were named according to the newly revised INN nomenclature scheme for cell-based substances, whereas tisagenlecleucel (117)(79) was named according to the nomenclature scheme of the USAN Council, as the name had already been adopted by USAN in 2014. Significantly, tisagenlecleucel (117)(79), also known under its trade name Kymriah, and axicabtagene ciloleucel (117)(79), using the trade name Yescarta, became the first genetically engineered cell therapy substances to be approved by the US FDA $[15,16]$.

Currently, the harmonized INN nomenclature scheme for CAR Tcell therapies follows the two-word scheme for CGT substances, whereby the first word describes the gene component with the gene infix -cabta- for cell-expressed antibody and T-cell activation and the 
Table 3

Summary of published CAR T-cell INN requests.

\begin{tabular}{|c|c|c|c|c|}
\hline Target antigen & INN & Condition & Approval status & Manufacturer code \\
\hline CD19 & $\begin{array}{l}\text { axicabtagene ciloleucel } \\
\left.\text { (117)(79)(YESCARTA }{ }^{2}\right)\end{array}$ & $\begin{array}{l}\text { - Relapsed/Refractory Diffuse Large B-Cell Lymphoma (DLBCL) } \\
\text { - primary mediastinal large B-cell lymphoma } \\
\text { - high-grade B-cell lymphoma } \\
\text { - Follicular lymphoma }\end{array}$ & $\begin{array}{l}\text { - FDA approved } \\
\text { - EMA approved }\end{array}$ & KTE-C19 \\
\hline CD19 & $\begin{array}{l}\text { tisagenlecleucel } \\
\qquad(117)(79)(\mathrm{KYMRIAH} \otimes)\end{array}$ & - Relapsed/refractory acute lymphoblastic leukemia (ALL) & $\begin{array}{l}\text { - FDA approved } \\
\text { - EMA approved }\end{array}$ & $\begin{array}{l}\text { CTL019 } \\
\text { CART19 }\end{array}$ \\
\hline CD19 & $\begin{array}{l}\text { vadacabtagene leraleucel } \\
\quad(117)(79)\end{array}$ & - Acute Lymphoblastic Leukemia (ALL) & $\begin{array}{l}\text { • EMA PRIME designation (withdrawn) } \\
\text { 9/15/2016 }\end{array}$ & JCAR015 \\
\hline BCMA & $\begin{array}{l}\text { idecabtagene vicleucel } \\
\quad(119)(81)\end{array}$ & - Relapsed/refractory (R/R) multiple myeloma & $\begin{array}{l}\text { - FDA orphan drug designation } \\
\text { 09/28/2017 } \\
\text { - EMA orphan designation } \\
04 / 20 / 2017\end{array}$ & bb2121 \\
\hline CD19 & $\begin{array}{l}\text { lisocabtagene maraleucel } \\
\quad(119)(81)\end{array}$ & $\begin{array}{l}\text { - Relapsed/refractory (R/R) aggressive large B-cell } \\
\text { Non-Hodgkin Lymphoma (NHL) } \\
\text { - relapsed/refractory diffuse large B-cell lymphoma (DLBCL) }\end{array}$ & $\begin{array}{l}\text { - FDA orphan drug designation } \\
\text { 09/07/2016 } \\
\text { - EMA PRIME designation } \\
\text { 12/15/2016 } \\
\text { - EMA orphan designation } \\
07 / 17 / 2017\end{array}$ & JCAR017 \\
\hline CD19 & $\begin{array}{l}\text { tebrocabtagene autoleucel } \\
(121)(83)\end{array}$ & - Relapsed/refractory (R/R) acute lymphoblastic leukemia & & TBI-1501 \\
\hline BCMA & $\begin{array}{l}\text { ciltacabtagene autoleucel } \\
(122)(84)\end{array}$ & - Relapsed/refractory (R/R) multiple myeloma & $\begin{array}{l}\text { - EMA orphan designation } \\
02 / 28 / 2020\end{array}$ & $\begin{array}{l}\text { JNJ-68284528 } \\
\text { JNJ-4528 }\end{array}$ \\
\hline BCMA & $\begin{array}{l}\text { orvacabtagene autoleucel } \\
(122)(84)\end{array}$ & - Relapsed/refractory (R/R) multiple myeloma & $\begin{array}{l}\text { - FDA orphan drug designation } \\
\text { 02/01/2019 } \\
\text { - EMA PRIME designation } \\
11 / 14 / 2019\end{array}$ & JCARH125 \\
\hline CD19 & $\begin{array}{l}\text { azercabtagene zapreleucel } \\
(123)(85)\end{array}$ & $\begin{array}{l}\text { - Relapsed/refractory (R/R) B-cell Non-Hodgkin Lymphoma } \\
\text { (NHL) }\end{array}$ & $\begin{array}{l}\text { - FDA orphan drug designation } \\
05 / 13 / 2020\end{array}$ & PBCAR0191 \\
\hline MSLN & $\begin{array}{l}\text { gavocabtagene autoleucel } \\
\quad(123)(85)\end{array}$ & - Mesothelioma & $\begin{array}{l}\text { - FDA orphan drug designation } \\
02 / 01 / 2019\end{array}$ & TC-210 \\
\hline CD19 & $\begin{array}{l}\text { obecabtagene autoleucel } \\
(123)(85)\end{array}$ & - Relapsed/refractory acute lymphoblastic leukemia (ALL) & $\begin{array}{l}\text { - FDA orphan drug designation } \\
11 / 04 / 2019\end{array}$ & AUT01 \\
\hline CD19 & $\begin{array}{l}\text { relmacabtagene autoleucel } \\
\quad(123)(85)\end{array}$ & $\begin{array}{l}\text { - Relapsed/refractory (R/R) B-cell Non-Hodgkin Lymphoma } \\
\text { (NHL) } \\
\text { - Relapsed/refractory acute lymphoblastic leukemia (ALL) }\end{array}$ & & JWCAR029 \\
\hline CD20 / CD19 & $\begin{array}{l}\text { zamtocabtagene autoleucel } \\
\text { (124) }\end{array}$ & - B-cell Non-Hodgkin Lymphoma (NHL) & $\begin{array}{l}\text { - EMA PRIME designation } \\
\text { 10/17/2019 } \\
\text { - EMA orphan designation } \\
08 / 21 / 2020\end{array}$ & MB-CART2019.1 \\
\hline CD19 & $\begin{array}{l}\text { brexucabtagene autoleucel } \\
\left.\text { (TECARTUS }{ }^{\circledR}\right)\end{array}$ & - Relapsed/Refractory (R/R) Mantle Cell Lymphoma & $\begin{array}{l}\text { - FDA approved } \\
\text { - EMA conditional approval }\end{array}$ & KTE-X19 \\
\hline
\end{tabular}

Abbreviations: CD19 (cluster of differentiation 19, also known as B-lymphocyte antigen CD19, B-lymphocyte surface antigen B4, T-cell surface antigen Leu-12 and differentiation antigen CD19); BCMA (B-cell maturation antigen, also known as tumor necrosis factor receptor superfamily member 17 (TNFRSF17)); MSLN (mesothelin, also known as pre-pro-megakaryocyte-potentiating factor, CAK1 antigene); CD20 (B-lymphocyte antigen CD20, also known as B-lymphocyte surface antigen B1, leukocyte surface antigen Leu-16, membrane-spanning 4-domains subfamily A member 1, Bp35).

second word describes the cell component. A distinction is made between allogeneic requests that contain a random prefix and autologous cells that have the prefix auto-.

Table 3 summarizes all CAR T-cell INN requests that have been published by the INN Programme up to pINN list 124. In addition, it lists brexucabtagene autoleucel, which has received FDA and European Medicines Agency approval for relapsed/refractory mantle cell lymphoma (Tables 4, 5) and is planned for publication in pINN list 125. As shown in Figure 2B, more CAR T-cell requests are currently being evaluated and are expected to be published in upcoming INN lists.
Furthermore, it should be noted that the field is evolving rapidly, and novel CAR T cell products are under development that aim to overcome current issues such as severe toxicity, limited use, and in particular, the lack of efficacy in solid tumors [14]. Among these new technologies are CAR-engineered natural killer cells for cancer therapy [17] and switchable adaptor CAR platforms [18], which are developed with the aim of improving the safety, flexibility and controllability of conventional CAR T cells. The evolution of CAR designs beyond their current conventional structure will eventually also reach the INN Programme and challenge the INN nomenclature to encompass these new therapeutic approaches 
Table 4

List of FDA approved cellular and gene therapy products (List of licensed products from the Office of Tissues and Advanced Therapies (OTAT) 24.7.2020)

\begin{tabular}{|c|c|c|c|}
\hline Brand name INN & Manufacturer & Approval date & Current status \\
\hline $\begin{array}{l}\text { - TECARTUS } \\
\text { brexucabtagene autoleucel }\end{array}$ & Kite Pharma, Inc. & Jul-2020 & $\begin{array}{l}\text { Approved } \\
\text { Link to FDA website }\end{array}$ \\
\hline $\begin{array}{l}\text { - ZOLGENSMA } \\
\text { onasemnogene abeparvovec-xioi }\end{array}$ & AveXis, Inc & May-2019 & $\begin{array}{l}\text { Approved } \\
\text { Link to FDA website }\end{array}$ \\
\hline • HPC, Cord Blood & MD Anderson Cord Blood Bank & Jun-2018 & $\begin{array}{l}\text { Approved } \\
\text { Link to FDA website }\end{array}$ \\
\hline $\begin{array}{l}- \text { LUXTURNA } \\
\text { voretigene neparvovec }\end{array}$ & Spark Therapeutics, Inc. & Dec-2017 & $\begin{array}{l}\text { Approved } \\
\text { Link to FDA website }\end{array}$ \\
\hline $\begin{array}{l}- \text { YESCARTA } \\
\text { axicabtagene ciloleucel }\end{array}$ & Kite Pharma, Incorporated & Oct-2017 & $\begin{array}{l}\text { Approved } \\
\text { Link to FDA website }\end{array}$ \\
\hline $\begin{array}{l}\bullet \text { KYMRIAH } \\
\text { tisagenlecleucel }\end{array}$ & Novartis Pharmaceuticals Corporation & Aug-2017 & $\begin{array}{l}\text { Approved } \\
\text { Link to FDA website }\end{array}$ \\
\hline $\begin{array}{l}\text { - MACI } \\
\text { (Autologous Cultured Chondrocytes on a Porcine Collagen Membrane) }\end{array}$ & Vericel Corporation & Dec-2016 & $\begin{array}{l}\text { Approved } \\
\text { Link to FDA website }\end{array}$ \\
\hline $\begin{array}{l}- \text { CLEVECORD } \\
\text { (HPC, Cord Blood) }\end{array}$ & Cleveland Cord Blood Center & Sep-2016 & $\begin{array}{l}\text { Approved } \\
\text { Link to FDA website }\end{array}$ \\
\hline $\begin{array}{l}- \text { ALLOCORD } \\
\text { (HPC, Cord Blood) }\end{array}$ & SSM Cardinal Glennon Children's Medical Center & Jan-2016 & $\begin{array}{l}\text { Approved } \\
\text { Link to FDA website }\end{array}$ \\
\hline • HPC, Cord Blood & Bloodworks & Jan-2016 & $\begin{array}{l}\text { Approved } \\
\text { Link to FDA website }\end{array}$ \\
\hline $\begin{array}{l}- \text { IMLYGIC } \\
\text { talimogene laherparepvec }\end{array}$ & Amgen Inc. & Oct-2015 & $\begin{array}{l}\text { Approved } \\
\text { Link to FDA website }\end{array}$ \\
\hline$\bullet$ HPC, Cord Blood & LifeSouth Community Blood Centers, Inc. & Jun-2013 & $\begin{array}{l}\text { Approved } \\
\text { Link to FDA website }\end{array}$ \\
\hline $\begin{array}{l}- \text { DUCORD } \\
\text { (HPC Cord Blood) }\end{array}$ & Duke University School of Medicine & Oct-2012 & $\begin{array}{l}\text { Approved } \\
\text { Link to FDA website }\end{array}$ \\
\hline$\bullet$ HPC, Cord Blood & Clinimmune Labs, University of Colorado Cord Blood Bank & May-2012 & $\begin{array}{l}\text { Approved } \\
\text { Link to FDA website }\end{array}$ \\
\hline $\begin{array}{l}\text { - GINTUIT } \\
\text { (Allogeneic Cultured Keratinocytes and Fibroblasts in Bovine Collagen) }\end{array}$ & Organogenesis Incorporated & Mar-2012 & $\begin{array}{l}\text { Approved } \\
\text { Link to FDA website }\end{array}$ \\
\hline $\begin{array}{l}\text { - HEMACORD } \\
\text { (HPC, Cord Blood) }\end{array}$ & New York Blood Center, Inc & Nov-2011 & $\begin{array}{l}\text { Approved } \\
\text { Link to FDA website }\end{array}$ \\
\hline $\begin{array}{l}- \text { LAVIV } \\
(\text { azficel-T*) }\end{array}$ & Fibrocell Technologies, Inc. & Jun-2011 & $\begin{array}{l}\text { Approved } \\
\text { Link to FDA website }\end{array}$ \\
\hline $\begin{array}{l}\text { - PROVENGE } \\
\text { (sipuleucel-T*) }\end{array}$ & Dendreon Corporation & Apr-2010 & $\begin{array}{l}\text { Approved } \\
\text { Link to FDA website }\end{array}$ \\
\hline
\end{tabular}

HPC, hematopoietic progenitor cell; FDA, Food \& Drug Adminstration; * USAN adopted name

within its naming scheme. The classical infix -cabta- for "cell expressed antibody and T-cell activation" might not always be appropriate in view of new CAR designs, and modifications have been discussed within the INN Programme. In the current scheme, the letter " $t$ " of the infix -cabtarefers to the T-cell component of these substances; however, in the case of CAR-engineered natural killer cells, this would no longer be appropriate. A small modification, such as a one-letter change from the letter " $t$ " to the letter " $n$ " for natural killer cells, might be an option. The infix -cabta- would also not be appropriate in the case of switchable adaptor CAR platforms such as Fc-binding adaptor CARs, for which the antibody is added separately and is no longer a "cell-expressed antibody." Here, a modification to -refta-, whereby ref would stand for "receptor of Fc" and ta for "T-cell activation," could be a possibility. These options remain under discussion by the WHO INN Programme.

\section{INN Applications for Personalized Medicines and Gene-Edited Substances}

The first personalized medicine that received an INN was autogene cevumeran (122)(84), a single-stranded mRNA that codes for up to 20 patient-specific tumor neoantigens that are derived from the patient's tumor. Genetic sequencing is used to identify up to 20 neoantigen epitopes that may elicit the strongest immune response. These patient-specific sequences encoding neoantigens are inserted between welldefined constant regions. This technology belongs to the group of mRNA-based personalized cancer vaccines and is expected to induce immunostimulatory and anti-neoplastic activity. The INN carries the stem -meran, as it falls into the same category as other mRNA-based substances that are developed for active immunization, such as the prophylactic RNA vaccine substances zorecimeran (124), abdavomeran
(124), tozinameran (124), ganulameran (124) and pidacmeran (124), currently developed for use against severe acute respiratory syndrome coronavirus 2. Although these substances for active immunization and other non-prophylactic substances in the -meran category do not contain a gene infix and follow a one-word naming scheme that consists of a random prefix followed by the suffix -meran, a two-word name approach was chosen in the case of autogene cevumeran to highlight the autologous character of this substance.

The second personalized medicine that was named is the cellbased gene therapy tacatresgene autoleucel, published in pINN list 124. This substance consists of patient-derived CD4 and CD8 T cells that are genome-engineered using CRISPR/Cas9 to express a patientderived, neoepitope-specific TCR, which replaces the endogenous TCR. The neoepitopes are identified and isolated from each patient's intrinsic T-cell cancer immune response, with a single patientderived, tumor-specific neo-TCR per T cell and a maximum of three different neo-TCRs in the final drug substance. Hence, the finished substance is likely to contain T cells targeting multiple antigens, yet the nomenclature scheme follows the classical nomenclature scheme for CGT substances, with the gene infix -tres- for "TCR engineered for specificity," as had been assigned to non-personalized variants such as olitresgene autoleucel (121)(83) and letetresgene autoleucel (121) (83), that contain only a single antigen-specific TCR. As the second word, autoleucel, indicates that this is an autologous, patient-derived substance, a second infix, -auto-, for the gene component was not further introduced. For tacatresgene autoleucel (124), the geneedited nature of the cell component was not highlighted in the INN itself and is only detailed in the definition paragraph. However, it should be noted that the position of the INN Programme regarding gene-edited substances might change in the future. A 
Table 5

List of EMA-approved cellular and gene therapy products

\begin{tabular}{|c|c|c|c|c|}
\hline BRAND NAME INN & Marketing-authorisation holder & Therapeutic area $(\mathrm{MeSH})$ & Approval date & Current status \\
\hline $\begin{array}{l}\text { - LIBMELDY } \\
\text { atidarsagene autotemcel }\end{array}$ & Orchard Therapeutics (Netherlands) BV & $\begin{array}{l}\text { Leukodystrophy, Metachromatic } \\
\text { (MLD) }\end{array}$ & 15 October 2020 & $\begin{array}{l}\text { Approved } \\
\text { Link to EMA website }\end{array}$ \\
\hline $\begin{array}{l}\text { - TECARTUS } \\
\text { brexucabtagene autoleucel }\end{array}$ & Kite Pharma EU B.V. & Lymphoma, Mantle cell (MCL) & 15 October 2020 & $\begin{array}{l}\text { Conditional approval } \\
\text { Link to EMA website }\end{array}$ \\
\hline $\begin{array}{l}\text { - ZOLGENSMA } \\
\text { onasemnogene abeparvovec }\end{array}$ & Novartis Gene Therapies EU Limited & Muscular Atrophy, Spinal & 18 May 2020 & $\begin{array}{l}\text { Conditional approval } \\
\text { Link to EMA website }\end{array}$ \\
\hline $\begin{array}{l}\text { - ZYNTEGLO } \\
\text { betibeglogene autotemcel }\end{array}$ & bluebird bio (Netherlands) B.V. & beta-Thalassemia & 29 May 2019 & $\begin{array}{l}\text { Conditional approval } \\
\text { Link to EMA website }\end{array}$ \\
\hline $\begin{array}{l}\text { - LUXTURNA } \\
\text { voretigene neparvovec }\end{array}$ & Novartis Europharm Limited & $\begin{array}{l}\text { Leber Congenital Amaurosis, } \\
\text { Retinitis Pigmentosa }\end{array}$ & 22 November 2018 & $\begin{array}{l}\text { Approved } \\
\text { Link to EMA website }\end{array}$ \\
\hline $\begin{array}{l}\text { - YESCARTA } \\
\text { axicabtagene ciloleucel }\end{array}$ & Kite Pharma EU B.V. & $\begin{array}{l}\text { Lymphoma, Follicular } \\
\text { Lymphoma, Large B-Cell, Diffuse }\end{array}$ & 23 August 2018 & $\begin{array}{l}\text { Approved } \\
\text { Link to EMA website }\end{array}$ \\
\hline $\begin{array}{l}\bullet \text { KYMRIAH } \\
\text { tisagenlecleucel }\end{array}$ & Novartis Europharm Limited & $\begin{array}{l}\text { Precursor B-Cell Lymphoblastic Leuke- } \\
\text { mia-Lymphoma } \\
\text { Lymphoma, Large B-Cell, Diffuse }\end{array}$ & 22 August 2018 & $\begin{array}{l}\text { Approved } \\
\text { Link to EMA website }\end{array}$ \\
\hline $\begin{array}{l}\text { - ALOFISEL } \\
\text { darvadstrocel }\end{array}$ & Takeda Pharma A/S & Rectal Fistula & 23 March 2018 & $\begin{array}{l}\text { Approved } \\
\text { Link to EMA website }\end{array}$ \\
\hline • SPHEROX & CO.DON AG & Cartilage diseases & 10 July 2017 & $\begin{array}{l}\text { Approved } \\
\text { Link to EMA website }\end{array}$ \\
\hline $\begin{array}{l}\text { - STRIMVELIS } \\
\text { simoladagene autotemcel }\end{array}$ & Orchard Therapeutics (Netherlands) BV & Severe Combined Immunodeficiency & 26 May 2016 & $\begin{array}{l}\text { Approved } \\
\text { Link to EMA website }\end{array}$ \\
\hline $\begin{array}{l}\text { - IMLYGIC } \\
\text { talimogene laherparepvec }\end{array}$ & Amgen Europe B.V. & Melanoma & 16 December 2015 & $\begin{array}{l}\text { Approved } \\
\text { Link to EMA website }\end{array}$ \\
\hline$\bullet$ HOLOCLAR & Holostem Terapie Avanzate s.r.l. & $\begin{array}{l}\text { Stem Cell Transplantation } \\
\text { Corneal Diseases }\end{array}$ & 17 February 2015 & $\begin{array}{l}\text { Conditional approval } \\
\text { Link to EMA website }\end{array}$ \\
\hline $\begin{array}{l}\text { ZALMOXIS } \\
\text { nalotimagene carmaleucel }\end{array}$ & MolMed SpA & $\begin{array}{l}\text { Hematopoietic Stem Cell Transplantation } \\
\text { Graft vs Host Disease }\end{array}$ & 18 August 2016 & $\begin{array}{l}\text { Withdrawn in } 2019 \\
\text { Link to EMA website }\end{array}$ \\
\hline PROVENGE & Dendreon UK Ltd & Prostatic Neoplasms & 6 September 2013 & $\begin{array}{l}\text { Withdrawn in } 2015 \\
\text { Link to EMA website }\end{array}$ \\
\hline MACI & Vericel Denmark ApS & Fractures, Cartilage & 27 June 2013 & $\begin{array}{l}\text { Suspended in 2014, expired in } \\
2018 \\
\text { Link to EMA website }\end{array}$ \\
\hline $\begin{array}{l}\text { GLYBERA } \\
\text { alipogene tiparvovec }\end{array}$ & uniQure biopharma B.V. & Hyperlipoproteinemia Type I & 25 October 2012 & $\begin{array}{l}\text { Expired in } 2017 \\
\text { Link to EMA website }\end{array}$ \\
\hline ChondroCelect & TiGenix N.V. & Cartilage Diseases & 5 October 2009 & $\begin{array}{l}\text { Withdrawn in } 2016 \\
\text { Link to EMA website }\end{array}$ \\
\hline
\end{tabular}

EMA, European Medicines Agency; MeSH, Medical Subject Headings

new infix, -ged-for "gene editing" is currently being discussed to indicate that cells have been genome-engineered, which could result in cell component names that end in the stem -gedleucel or -gedtemcel.

\section{Discussion}

With the advent of new technologies, such as gene editing and personalized medicine, the field is constantly evolving and becoming increasingly complex. The INN Programme has adapted to this development with a revision of the application process and through adjustment of the nomenclature scheme. As only a minimal amount of information can be included in the name itself without creating names that become overly long and unpronounceable, particular importance resides in the detailed descriptive paragraph that is published together with the INN in the WHO Drug Information. It is significant that the information requested from INN applicants for CT/CGT substances includes details regarding the manufacture of the substance. These are the only INN for which the manufacturing aspects impinge on the INN assignment.

The precise characterization and naming of CT/CGT substances as part of the regulatory process are especially important, as many cell therapies are marketed directly to patients without appropriate regulatory control. Direct-to-consumer marketing of unproven cell-based interventions is a serious health issue and includes those that claim to treat coronavirus disease 2019, which is particularly concerning during this current, devastating global pandemic [19,20]. At the moment, there is a limited number of both immune and stem cell products with marketing authorization (Tables 4, 5), and the current state of scientific evidence does not justify the use of most cell-based interventions outside of well-designed, strictly supervised and regulated clinical research studies $[21,22]$. In this context, an INN together with a distinct descriptive paragraph helps stakeholders and patients clearly distinguish those unproven cell-based interventions from cell therapies that have undergone a regulatory process. To ensure patient safety and pharmacovigilance, it is therefore crucial that the INN Programme continues to adjust to this increasingly complex landscape and carefully defines cell-based INN. With the revision of the application form, the INN Programme now has a tool at hand that will strengthen the precise definition of cell-based therapies and contribute to the regulation of these substances.

\section{Funding}

No funding was received.

\section{Declaration of Competing Interest}

The authors have no commercial, proprietary or financial interest in the products or companies described in this article. 


\section{Author Contributions}

Conception and design of the study: UL, MR, JSR, RB. Acquisition of data: UL. Analysis and interpretation of data: UL, RB. Drafting or revising the manuscript:UL, MD, TM, MR, JSR, SGK, MT, RB. All authors have approved the final article.

\section{Acknowledgments}

The authors thank Dr Lilia Bi, US FDA, Center for Biologics Evaluation and Research; Professor Kai Gao, School of Life Sciences, Shanghai University, China; Dr David Lewis, US FDA, Center for Drug Evaluation and Research; Dr Mercy Quagraine, US FDA, Center for Biologics Evaluation and Research; Dr Ralf Sanzenbacher, Paul-Ehrlich-Institut; Dr Yoji Sato, National Institute of Health Sciences, Japan; Dr Si-Hyung Yoo, Norms and Standards for Biological Products, WHO; Dr Eloisa Zgraggen, WHO INN Programme; and Stephanie Shubat, USAN Program, for their essential assistance and technical contribution.

\section{Supplementary materials}

Supplementary material associated with this article can be found in the online version at doi:10.1016/j.jcyt.2021.02.114.

\section{References}

[1] International Nonproprietary Names: revised procedure (EB115/11), 2004. https://apps.who.int/gb/ebwha/pdf_files/EB115/B115_11-en.pdf. Accessed 24 March, 2021

[2] Ho B, Baryshnikova A, Brown GW. Unification of Protein Abundance Datasets Yields a Quantitative Saccharomyces cerevisiae Proteome. Cell Syst 2018;6(2). 192-205.e3.

[3] Mullard A. Gene-editing pipeline takes off. Nat Rev Drug Discov 2020;19(6):367-72.

[4] World Health Organization. The use of stems in the selection of International Nonproprietary Names (INN) for pharmaceutical substances. Geneva, Switzerland: World Health Organization; 2018.

[5] International Nonproprietary Names (INN) for biological and biotechnological substances (a review). 2016. https://www.who.int/medicines/services/inn/BioReview2016.pdf. Accessed 24 March, 2021.

[6] International Nonproprietary Names for Pharmaceutical Substances (INN): proposed INN: list 115 WHO Drug Information. World Health Organization 2016;30 (2):241-357.
[7] ELTRAPULDENCEL-T, Statement on a Nonproprietary Name adopted by the USAN Council, American Medical Association (AMA). https://searchusan.amaassn.org/usan/documentDownload?uri=\%2Funstructured\%2Fbinary\%2Fusan\% 2Feltrapuldencel-t.pdf. Accessed 24 March, 2021. United States Adopted Name (USAN) Drug Finder.

[8] STAPULDENCEL-T, Statement on a Nonproprietary Name adopted by the USAN Council, American Medical Association (AMA). https://searchusan.ama-assn.org/ usan/documentDownload?uri=\%2Funstructured\%2Fbinary\%2Fusan\%2Fstapuldencel-t.pdf. Accessed 24 March, 2021. United States Adopted Name (USAN) Drug Finder.

[9] Robertson JS, Chui WK, Genazzani AA, Malan SF, López de la Rica Manjavacas A, Mignot G, Thorpe R, Balocco R, Rizzi M. The INN global nomenclature of biological medicines: A continuous challenge. Biologicals 2019;60:15-23.

[10] International Nonproprietary Names (INN) for biological and biotechnological substances (a review). 2019. https://www.who.int/medicines/services/inn/BioReview2019.pdf. Accessed 24 March, 2021.

[11] 67th Consultation on International Nonproprietary Names for pharmaceutical substances. Executive summary. 2018. https://www.who.int/medicines/services/ inn/67th_Executive_Summary.pdf. Accessed 24 March, 2021.

[12] 70th Consultation on International Nonproprietary Names for pharmaceutica substances. Executive summary. 2020. https://www.who.int/medicines/services/ inn/70th_Executive_Summary.pdf. Accessed 24 March, 2021.

[13] Cell-based therapies: Mandatory information for INN selection and publication. Annex to INN Application Form 2020. https://www.who.int/medicines/services/ inn/20_478_Annex_INN_Form_cell_20200518.pdf?ua=1. Accessed 24 March, 2021.

[14] Rafiq S, Hackett CS, Brentjens RJ. Engineering strategies to overcome the current roadblocks in CAR T cell therapy. Nat Rev Clin Oncol 2020;17(3):147-67.

[15] KYMRIAH (tisagenlecleucel). https://www.fda.gov/vaccines-blood-biologics/ cellular-gene-therapy-products/kymriah-tisagenlecleucel. Accessed 24 March, 2021.

[16] YESCARTA (axicabtagene ciloleucel). https://www.fda.gov/vaccines-blood-biologics/cellular-gene-therapy-products/yescarta-axicabtagene-ciloleucel. Accessed 24 March, 2021.

[17] Xie G, Dong H, Liang Y, Ham JD, Rizwan R, Chen J. CAR-NK cells: A promising cellular immunotherapy for cancer. EBioMedicine 2020;59:102975.

[18] Arndt C, Fasslrinner F, Loureiro LR, Koristka S, Feldmann A, Bachmann M. Adaptor CAR Platforms-Next Generation of T Cell-Based Cancer Immunotherapy. Cancers (Basel) 2020;12(5):1302.

[19] Marks PW, Hahn S. Identifying the Risks of Unproven Regenerative Medicine Therapies. JAMA 2020;324(3):241-2.

[20] Turner L. Preying on Public Fears and Anxieties in a Pandemic: Businesses Selling Unproven and Unlicensed "Stem Cell Treatments" for COVID-19. Cell Stem Cell 2020;26(6):806-10.

[21] Cuende N, Rasko JEJ, Koh MBC, Dominici M, Ikonomou L. Cell, tissue and gene products with marketing authorization in 2018 worldwide. Cytotherapy 2018;20 (11):1401-13.

[22] Marks P, Gottlieb S. Balancing Safety and Innovation for Cell-Based Regenerative Medicine. N Engl J Med 2018;378(10):954-9. 